\title{
Adherence to Antipsychotic Medication and Quality of Life in Latin-American Patients Diagnosed with Schizophrenia
}

This article was published in the following Dove Press journal: Patient Preference and Adherence

\section{Alejandra Caqueo- \\ Urízar (D) \\ Alfonso Urzúa $\mathbb{I D}^{2}$ \\ Patricio Mena- \\ Chamorro (iD) ${ }^{3}$ \\ Guillaume Fond (D) ${ }^{4}$ \\ Laurent Boyer (1D ${ }^{4}$}

'Instituto de Alta Investigación, Universidad de Tarapacá, Arica, Chile; ${ }^{2}$ Escuela de Psicología, Universidad Católica del Norte, Antofagasta, Chile; ${ }^{3}$ Escuela de Psicología y Filosofía, Universidad de Tarapacá, Arica, Chile; ${ }^{4}$ Aix-Marseille Univ, EA 3279 - Public Health, Chronic Diseases and Quality of Life - Research Unit, Marseille I3005, France
Correspondence: Alejandra Caqueo-

Urízar

Instituto de Alta Investigación,

Universidad de Tarapacá, Antofagasta

1520, Arica, Chile

Tel +56-58-2205079

Email acaqueo@academicos.uta.cl
Purpose: The purpose of this study was to describe the association between adherence to antipsychotic medication and quality of life $(\mathrm{QoL})$ in a sample of individuals diagnosed with schizophrenia.

Methods: Two hundred fifty-three patients were included from three public mental health services from Bolivia, Peru, and Chile. Data were collected using the Drug Attitude Inventory (DAI-10) and the Schizophrenia Quality of Life short-version questionnaire (SQoL-18), which considers 8 dimensions.

Results: Significant associations were found between adherence to antipsychotic medication treatment and QoL (S-QoL-18 index: $\beta=0.26, p=0.004$; self-esteem: $\beta=0.37, p=0.000$; and sentimental life: $\beta=0.20, p=0.033$ ). Associations of clinical and socio-demographic variables with QoL were identified: severity of psychotic symptoms, awareness of the disease, gender, age, and ethnicity were found to be associated with a lower level of QoL ( $\beta$ from $0.14-0.56$ ).

Conclusion: This study provides evidence of the association between adherence to treatment and quality of life in patients diagnosed with schizophrenia. Therefore, as in developed countries, improving adherence to antipsychotic medication would appear to be an important issue to address to improve patients' QoL in Latin American countries.

Keywords: adherence, quality of life, schizophrenia, Latin-American

\section{Introduction}

Patients diagnosed with schizophrenia have been seen to have low adherence to antipsychotic medication treatment (poor adherence ranging from $20 \%$ to $89 \%$ ). ${ }^{1-6}$ Moreover, $30 \%$ to $50 \%$ of the patients change the dose and rate of medication after hospital discharge without consulting a clinician. ${ }^{7-9}$

Among the most important risk factors for relapse, re-hospitalization, and resistance to treatment in patients diagnosed with schizophrenia, non-adherence to pharmacological treatment stands out, which is also associated with substance abuse, suicide attempts, violence, and the deterioration of long-term functioning in these patients. ${ }^{10,11}$ Non-adherence is considered a complex phenomenon, which could be influenced by four factors: sociodemographic variables, psychotic symptomatology (including persecutory delusion, hostility, and cognitive impairment), variables related to treatment (frequency and intensity of side effects, subjective feeling under treatment, comorbid addiction, duration of treatment, and addictive behavior), and insight into the disorder. ${ }^{12-15}$ 
Quality of life (QoL) is severely impaired in patients diagnosed with schizophrenia. ${ }^{16}$ QoL and adherence to antipsychotics in patients have been studied extensively and independently. ${ }^{17-19}$ Some studies suggested that nonadherence may be associated with impaired QoL, beginning from the first psychotic episode. ${ }^{19-21}$ Recent studies have suggested that improving adherence to pharmacological treatment may be a key to improving QoL in patients. ${ }^{22,23}$ Non-adherence may impact QoL through psychotic exacerbations. ${ }^{9,24}$ Most of this research has been carried out in industrialized countries, but little is known about countries where health resources are scarce and important mental health inequalities exist, such as in Latin-American countries. ${ }^{13}$

The objective of this study was to assess the associations between poor adherence and impaired QoL in community-dwelling outpatients diagnosed with schizophrenia in three Latin American countries: Peru, Bolivia, and Chile.

\section{Methods}

\section{Design and Setting}

This study is part of a larger international research project, which involved the participation of patients from three Latin American countries. It is a non-experimental study, whose design is transversal ex post facto retrospective, with a correlated scope because the variables were measured at one point in time and the phenomenon had already occurred.

\section{Participants}

This study used a convenience sampling strategy and was conducted in three Latin American countries, specifically in the cities of Arica in Northern Chile, Tacna in Southern Peru, and La Paz, the Capital of Bolivia. In 2019, the population of the cities of Arica and Tacna was approximately 250 thousand residents each, while in La Paz, there are approximately 2.7 million residents. The three mental health service systems are characterized by attendance to a large number of patients with diverse diagnoses of mental disorders.

This study used the inclusion criterion the condition that all patients had a diagnosis of schizophrenia according to the ICD-10 and were stabilized, that is, they had not experienced a psychotic episode in the last 6 months. The diagnosis was given by the psychiatrist of each Mental Health Service, ${ }^{25}$ excluding all patients with a current acute episode or a sensory or cognitive impairment that prevented them from being evaluated.

\section{Procedure}

Initially, the lead author examined the total number of patients diagnosed with schizophrenia in each department. Two clinical psychologists were trained to conduct interviews over a 3-month period in all three countries. Once the interviewers were trained, patients were invited to participate during their monthly follow-up visits. Before the assessment began, those who agreed to participate were asked for and provided informed consent. The assessment lasted 20-30 minutes, was made in pencil and paper format, and no compensation was offered.

\section{Instruments}

\section{Adherence to Antipsychotic Medication}

The Drug Attitude Inventory (DAI-10) ${ }^{26}$ is a brief 10 -item scale designed to assess experiences, attitudes, and beliefs about antipsychotic drugs. This scale contains items such as "I take medications of my own free choice," "Medication makes me feel tired and sluggish," or "My thoughts are clear on medication". Response options range from -10 (very bad attitude) to +10 (best possible attitude), where scores of 6 to 10 consider the patient to be adherent, 0 to 5 moderately adherent, and negative scores as nonadherent. ${ }^{26-28}$ The scale reported evidence of validity based on the relationship with other variables, where it was significantly associated with PANSS and GAF, in addition to showing adequate test-retest reliability (0.79). ${ }^{27,28}$ The Spanish version, adapted and translated by Ramírez, Robles, Salazar, and Páez, ${ }^{29}$ also showed evidence of validity based on relationship with other variables through association with the treatment attitude questionnaire (ITAQ) $(\mathrm{r}=0.47 ; p=0.001)$ and levels close to acceptable internal consistency (0.57).

\section{Quality of Life of Patients with Schizophrenia}

The Schizophrenia Quality of Life Questionnaire (SQoL$18)^{30}$ is an 18-item scale designed to assess quality of life in patients diagnosed with schizophrenia across 8 dimensions: psychological well-being (PsW), self-esteem (SE), family relationships (RFa), relationships with friends (RFr), resilience (RE), physical well-being ( $\mathrm{PhW}$ ), autonomy (AU), and sentimental life (SL). This scale contains items such as "I feel free to make decisions," "I am helped and supported by my family," or "I feel cut off from the outside world." The dimension and index scores range 
from 0 to 100 , where the higher the score, the higher the quality of life. The factor structure of the scale accounted for $78 \%$ of the total variance and showed satisfactory levels of internal consistency (Cronbach's alpha coefficients ranged from 0.72 to 0.84 ). This scale has been adapted and translated for Latin American countries, reporting the same factor structure as the original scale, adequate levels of internal consistency (Cronbach's alpha coefficient $>0.70$ ) and significant associations with PANSS. $^{31}$

\section{Socio-Demographic Data}

Data were collected on patients' gender, age, educational level, marital status, and ethnicity. Aymara is an ethnic minority that faces complex interculturality issues across the 3 countries despite a long tradition of indigenous and interbreeding, particularly in Perú and Bolivia. ${ }^{32}$

\section{Clinical Data}

Psychotic symptoms were assessed using the Positive And Negative Syndrome scale for Schizophrenia (PANSS). ${ }^{33}$ A 30-item questionnaire was designed to specifically assess psychotic symptoms in individuals diagnosed with schizophrenia in 5 dimensions: positive, negative, cognitive, depressive, and excitement psychopathology. The PANSS was translated and validated in Spanish by Peralta and Cuesta. ${ }^{34}$ Both the original and adapted versions showed evidence of adequate construct validity and modest internal consistency (Cronbach's alpha coefficient $>0.60$ ). Furthermore, data were collected on the duration of the illness in years and the type of mental health treatment. Finally, the scale to assess unawareness of mental disorder (SUMD) ${ }^{35}$ was used to measure awareness of the illness (insight). High scores represent a lack of awareness. The SUMD was translated and validated in Spanish by Ruiz and collaborators. ${ }^{36}$ Both the original and adapted versions showed satisfactory levels of internal consistency (Cronbach's alpha coefficient $>0.70$ ).

\section{Ethical Concerns}

This study complied with the Declaration of Helsinki.

The study was approved by the Ethics Committee of the University of Tarapacá and the National Health Service of Chile and was authorized by the directors of the Public Mental Health Services of Bolivia and Peru. Before commencement of the survey, written informed consent was requested from the patient. The objectives of the study and the voluntary and anonymous nature of participation were explained. No compensation was offered for participation in the study.

\section{Statistical Analysis}

All analyses were performed using Statistical Package for the Social Sciences (SPSS) version 25. ${ }^{37}$ To characterize the sample, means, proportions, and standard deviations were obtained for each variable. Associations between S-QoL18, DAI-10, and PANNS scores were performed using Spearman correlation test since previous analysis using the Kolmogorov-Smirnov test showed that the sample was not normally distributed $(p=0.000)$.

To identify the potential association between adherence to antipsychotic medication and quality of life, multiple linear regression analyses were performed. The dimensions of S-QoL18 and its total index were considered as separate dependent variables. To introduce the DAI-10 variable in the regression models, it was categorized as non-adherent, moderate, and adherent, and transformed into a dummy variable: therefore, moderate and adherent were considered as separate independent variables. Further, in an effort to control for the influence of clinical and socio-demographic variables on regression models, psychotic symptoms, awareness of the disease, type of mental health treatment, gender, age, educational level, marital status, and ethnicity were included. The final multiple regression models were reported using the standardized beta coefficients, which represent changes in the standard deviation of the dependent variable (S-QoL18) based on the change of one standard deviation in the different independent variables. Independent variables with larger beta standardized coefficients suggest a higher effect on the QoL of patients diagnosed with schizophrenia.

An ANOVA test was used to analyze the differences in means in each dimension of QoL between the different degrees of adherence (three groups: adherent, moderate, and non-adherent). In groups in which a significant difference between means was found, a post hoc analysis of multiple comparisons was carried out using the Bonferroni method.

\section{Results}

Two hundred and fifty-three patients diagnosed with schizophrenia were included from public mental health services. Of the participants, $32.8 \%$ were from Bolivia, $33.6 \%$ from Chile, and 33.6\% from Peru. The DAI-40 questionnaire was completed by 247 of the participants. 
The mean age of participants was 35.6 years $(\mathrm{SD}=15.5)$, $164(66.4 \%)$ were men, 237 (93.6\%) did not have a partner, and $213(84.2 \%)$ had less than 12 years of education. In the ethnic group, $117(46.2 \%)$ were Aymara. The DAI-10 scores showed moderate adherence to antipsychotic treatment (3.0, $\mathrm{SD}=4.8)$. Overall, $49(19.8 \%)$ participants were considered nonadherent. The prevalence of nonadherence was $11.8 \%$ in Chile, $25.0 \%$ in Peru, and 23.2\% in Bolivia. S-QoL index scores showed moderate levels of quality of life $(54.3, \mathrm{SD}=14.4)$. Figure 1 shows the participation flowchart. Sociodemographic details are shown in Table 1.

Spearman correlation analysis showed that the PANSS total score had statistically significant inverse correlations with S-QoL18 index $(\mathrm{r}=-.36)$, psychological well-being $(\mathrm{PsW})(\mathrm{r}=-.27)$, self-esteem $(\mathrm{SE})(\mathrm{r}=-.21)$, family relationships $(\mathrm{RFa})(\mathrm{r}=-.16)$, relationships with friends (RFr) $(\mathrm{r}=-.16)$, resilience $(\mathrm{RE})(\mathrm{r}=-.15)$, physical well-being $(\mathrm{PhW})(\mathrm{r}=-.19)$, autonomy (AU) $(\mathrm{r}=-.26)$, and sentimental life (SL) $(\mathrm{r}=-.31)$. The DAI-10 score, unlike the PANSS total score, had direct, statistically significant correlations with the S-QoL18 index $(r=0.18)$ and self-esteem (SE) $(r=0.26)$.

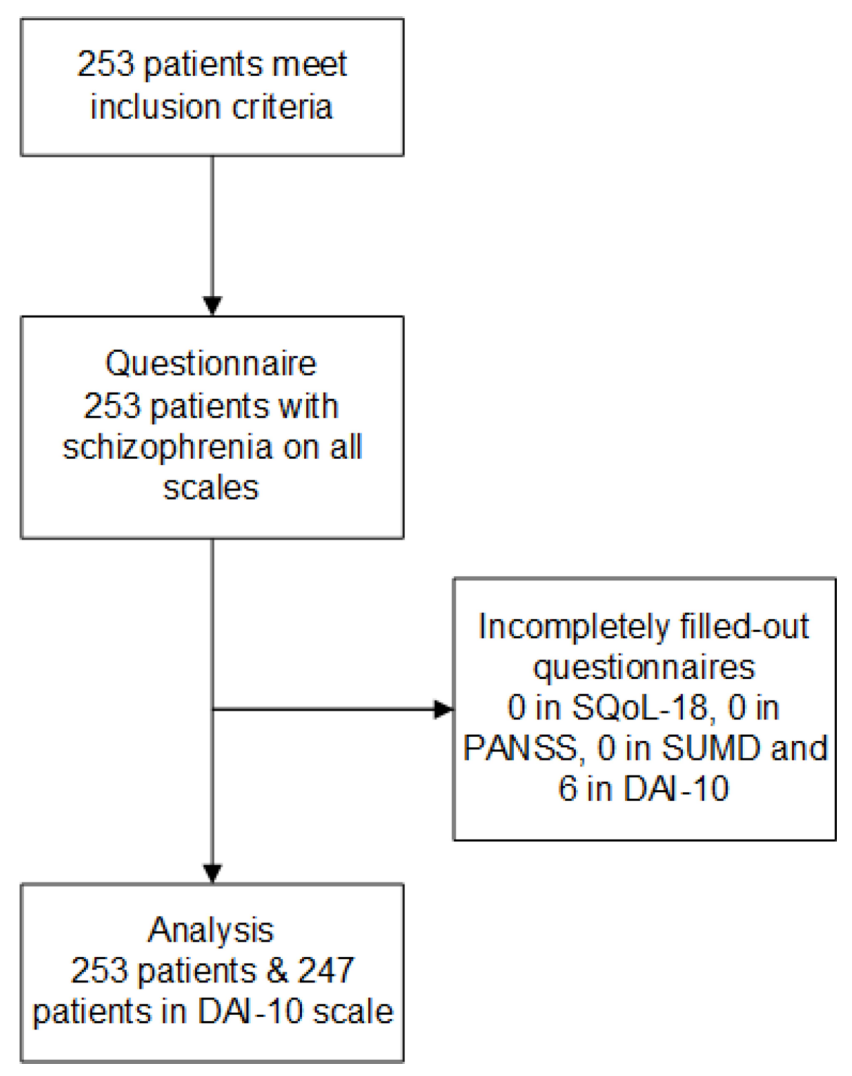

Figure I Patient flowchart.
In the multiple linear regression models, moderate adherence was significantly associated with the S-QoL18 index $(\beta=$ $0.23 ; p=0.008)$, the dimensions of self-esteem (SE) $(\beta=0.22$; $p=0.018)$, family relationships $(\mathrm{RFa})(\beta=0.23 ; p=0.013)$, autonomy (AU) $(\beta=0.21 ; p=0.023)$, and sentimental life (SL) $(\beta=0.19 ; p=0.031)$, while adherence was significantly associated with the S-QoL18 index $(\beta=0.26 ; p=0.004)$, the dimensions of self-esteem (SE) $(\beta=0.36 ; p=0.000)$, and sentimental life (SL) $(\beta=0.20 ; p=0.041)$, suggesting that patients with greater adherence to antipsychotic treatment will have better QoL. Clinical variables, such as the severity of psychotic symptoms measured by PANSS, showed significant relationships with the S-QoL18 index $(\beta=-.44 ; p=0.000)$ and autonomy (AU) $(\beta=0.28 ; p=0.000)$. The awareness of the patients evaluated through the SUMD scale showed significant relationships with the S-QoL18 index $(\beta=0.34 ; p=$ $0.000)$, psychological well-being (PsW) $(\beta=0.18 ; p=0.017)$, self-esteem (SE) $(\beta=27 ; p=0.001)$, relationships with friends (RFr) $(\beta=0.17 ; p=0.042)$, physical well-being $(\mathrm{PhW})(\beta=$ $0.28 ; p=0.001)$, autonomy (AU) $(\beta=0.20 ; p=0.014)$, and sentimental life $(\mathrm{SL})(\beta=0.35 ; p=0.000)$, which implies that, the greater the lack of awareness, the higher the QoL levels of patients. Furthermore, the duration of the disorder was significantly associated with resilience $(\mathrm{RE})(\beta=0.44 ; p=0.002)$ and physical well-being $(\mathrm{PhW})(\beta=0.31 ; p=0.029)$. Finally, the type of mental health treatment was only significantly associated with resilience (RE) $(\beta=0.16 ; p=0.028)$. Sociodemographic variables also showed significant relationships with QoL: women had lower levels for the family relationship dimension $(\mathrm{RFa})(\beta=-.28 ; p=0.000)$. Aymara patients had lower levels for sentimental life (SL) $(\beta=-.19$; $p=0.002)$, and older patients had lower levels of S-QoL18 $(\beta=-.39 ; p=0.003)$, self-esteem (SE) $(\beta=-.29 ; p=0.036)$, resilience $(\mathrm{RE})(\beta=-.56 ; p=0.000)$, and physical well-being $(\mathrm{PhW})(\beta=-.34 ; p=0.014)$ than younger patients. Finally, educational level was significantly associated with the S-QoL18 index $(\beta=0.21 ; p=0.001)$, psychological wellbeing $(\mathrm{PsW})(\beta=0.31 ; p=0.000)$, self-esteem $(\mathrm{SE})(\beta=0.14$; $p=0.038)$, autonomy $(\mathrm{AU})(\beta=0.16 ; p=0.022)$, and sentimental life $(\beta=0.11 ; p=0.015)$. All multiple regression models were able to predict between $4 \%$ and $26 \%$ of the variation in QoL levels, with the clinical variables standing out as the most predictive. The details of the multiple linear regression models are shown in Table 2.

The one-factor ANOVA shows that non-adherence has lower levels in all dimensions except the physical wellbeing dimension. In addition, only statistically significant differences were observed between the degree of adherence 
Table I Sociodemographic Characteristics of Sample $(N=253)$

\begin{tabular}{|c|c|c|}
\hline \multicolumn{2}{|l|}{ Patients } & \multirow{2}{*}{$\begin{array}{l}\text { M (SD) } \pm \text { Range or } \\
\text { N (\%) } \\
164(66.4 \%)\end{array}$} \\
\hline Gender (men) & & \\
\hline Age & & $35.6(15.5) \pm 15-73$ \\
\hline Aymara & $\begin{array}{l}\text { Yes } \\
\text { No }\end{array}$ & $\begin{array}{l}117(46.2 \%) \\
136(53.8 \%)\end{array}$ \\
\hline Marital status & $\begin{array}{l}\text { With a partner } \\
\text { Without a partner }\end{array}$ & $\begin{array}{l}16(6.3 \%) \\
237(93.6 \%)\end{array}$ \\
\hline $\begin{array}{l}\text { Educational level } \\
(\geq 12 \text { years) }\end{array}$ & & 40 (15.8\%) \\
\hline Illness duration (years) (ID) & & $14.6(11.8) \pm 0-55$ \\
\hline $\begin{array}{l}\text { Type of mental health } \\
\text { treatment }\end{array}$ & $\begin{array}{l}\text { Only } \\
\text { pharmacological } \\
\text { Integrated }\end{array}$ & $\begin{array}{l}222(87.7 \%) \\
31(12.3 \%)\end{array}$ \\
\hline DAl-10 score & & $3.0(4.8) \pm-10.0-10.0$ \\
\hline DAI-10 categorized & $\begin{array}{l}\text { Non-adherent } \\
\text { Moderate } \\
\text { Adherent } \\
\text { Missing }\end{array}$ & $\begin{array}{l}49(19.8 \%) \\
100(39.5 \%) \\
98(38.7 \%) \\
6(2.0 \%)\end{array}$ \\
\hline S-QoLI8 & $\begin{array}{l}\text { PsW } \\
\text { SE } \\
\text { RFa } \\
\text { RFr } \\
\text { RE } \\
\text { PhW } \\
\text { AU } \\
\text { SL } \\
\text { Index }\end{array}$ & $\begin{array}{l}47.6(24.7) \pm 0.0-100.0 \\
57.3(22.3) \pm 0.0-100.0 \\
63.2(23.3) \pm 0.0-100.0 \\
37.3(38.3) \pm 0.0-100.0 \\
68.4(17.5) \pm 0.0-91.6 \\
58.2(21.5) \pm 0.0-100.0 \\
57.0(22.6) \pm 0.0-100.0 \\
45.2(27.6) \pm 0.0-100.0 \\
54.3(14.4) \pm 0.0-100.0\end{array}$ \\
\hline PANSS & $\begin{array}{l}\text { Positive factor } \\
\text { Negative factor } \\
\text { Cognitive factor } \\
\text { Depression factor } \\
\text { Excitement factor } \\
\text { PANSS total }\end{array}$ & $\begin{array}{l}8.3(4.6) \pm 3.0-21.0 \\
18.6(8.3) \pm 6.0-37.0 \\
7.3(4.0) \pm 3.0-20.0 \\
6.4(3.7) \pm 3.0-20.0 \\
11.5(5.9) \pm 7.0-44.0 \\
71.3(28.2) \pm 30.0-191.0\end{array}$ \\
\hline SUMD & & $7.1(4.4) \pm 2.0-15.0$ \\
\hline
\end{tabular}

Notes: M (SD), Mean (standard deviation); N, Number of people; (\%), Effective (percentage); S-QoLI8, High scores suggest a better quality of life; DAI-10, High scores suggest a better attitude towards medication.

Abbreviations: S-QoLI8, PsW psychological well-being, SE self-esteem; RFa, family relationships; RFr, relationships with friends; RE, resilience; PhW, physical well-being; AU, autonomy; SL, sentimental life; DAI-I0, Drug Attitude Inventory; PANSS, Positive and Negative Syndrome Scale; SUMD, Scale to assess Unawareness of Mental Disorder.

and S-QoL18 index $\left(\mathrm{F}_{(2,243)}=4.370 ; p=0.014\right)$ and the self-esteem (SE) dimension $\left(\mathrm{F}_{(2,244)}=8.435 ; \mathrm{p}=0.000\right)$, while no significant differences were found in the other QoL dimensions. Details of the differences between the degree of adherence and QoL dimensions are presented in Table 3.
Post-hoc analysis showed that the mean S-QoL18 index score of the non-adherent group was significantly lower than that of the moderately adherent group ( $p=$ $0.032)$ and the adherent group $(p=0.016)$, while no statistically significant difference was observed between the moderately adherent group and the adherent group. When analyzing subdimensions, only self-esteem (SE) was significantly impaired in the non-adherent group compared to the moderately adherent group $(p=0.006)$ and the adherent group $(p=0.000)$. No significant differences were found between the moderately adherent group and the adherent group. The details of the post hoc analysis (one-way ANOVA) between the degree of adherence and QoL dimensions are presented in Table 4.

\section{Discussion}

The present study has shown a significant positive correlation between medication non-adherence and impaired QoL in community-dwelling subjects with schizophrenia. These results are similar to those of previous studies. ${ }^{19,21,22}$ Indeed, it is possible that as Puschner and collaborators ${ }^{18}$ indicated that medication non-adherence might affect patients' QoL "indirectly" via severity associated with uncontrolled symptomatology and/or side effects produced by the drugs.

Considering the control of clinical and sociodemographic variables, regression models also showed that adherence and moderate adherence, as opposed to non-adherence, influence the increase in self-esteem (SE), sentiment life (SL), family relationship (RFa), and autonomy (AU), which translates into higher levels of quality of life. These findings are consistent with a considerable number of studies showing that compliance with medication is beneficial for the stabilization of the psychopathological state and therefore higher levels of QoL for schizophrenia patients. ${ }^{23,38,39}$

In relation to the influence of clinical variables, the severity of psychotic symptoms is found to be associated with low quality of life in patients diagnosed with schizophrenia. Several studies have reported that the intensity and durability of psychotic symptomatology reduces the QoL of patients, in addition to highlighting it as one of the key variables in the increase or decrease of QoL. ${ }^{40-42}$ Similarly, awareness of the disease was associated with lower levels of QoL, expressed through lower psychological well-being (PsW), self-esteem (SE), relationships with friends (RFr), physical well-being ( $\mathrm{PhW}$ ), autonomy (AU), and sentimental life (SL). Some reasons that could explain 


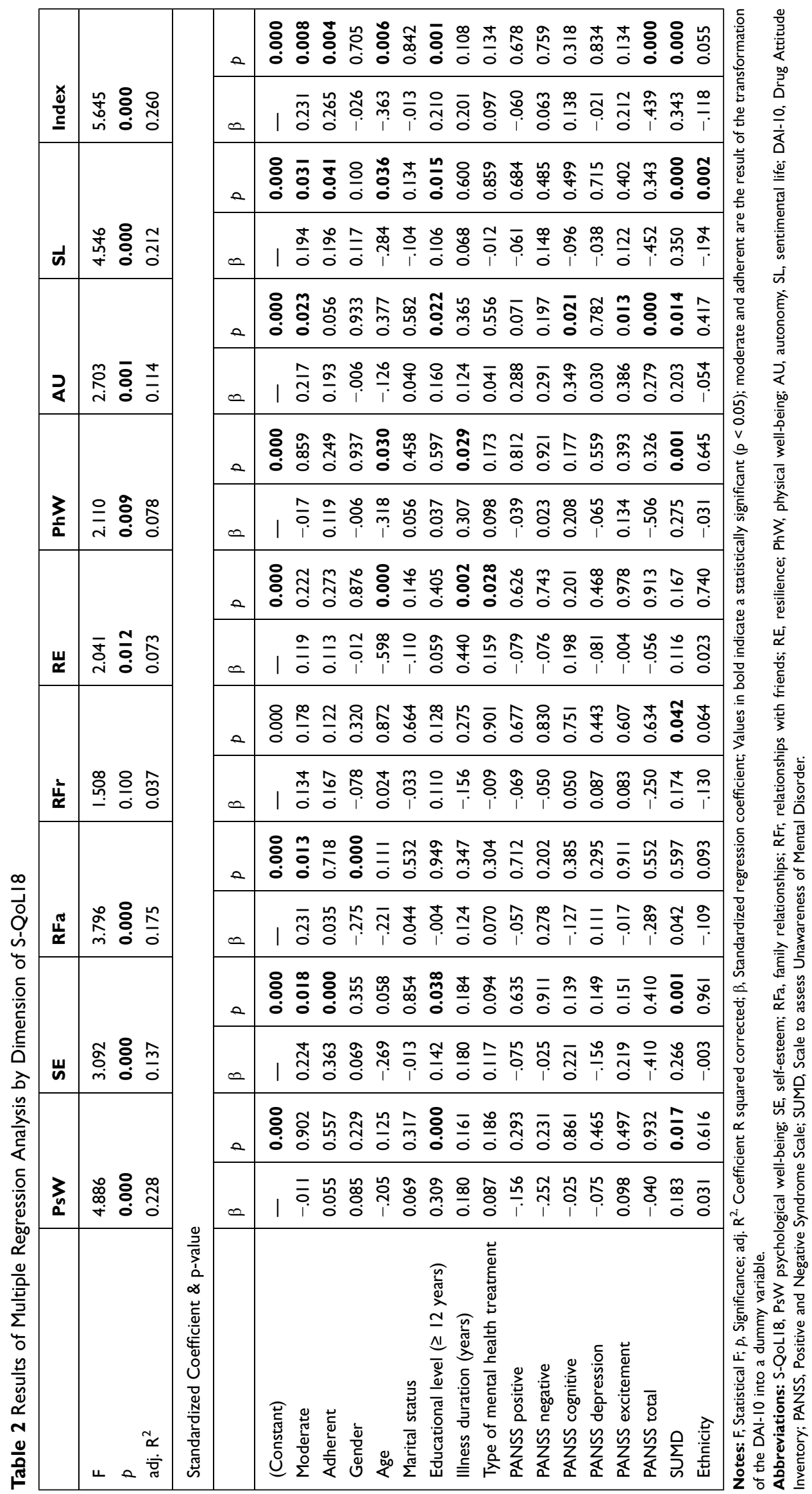


Table 3 Mean Differences (One-Way ANOVA) in Medication Adherence and Quality of Life

\begin{tabular}{|c|c|c|c|c|c|c|c|c|}
\hline \multicolumn{9}{|l|}{ DAI-I0 } \\
\hline \multirow[t]{2}{*}{ S-QoLI 8} & \multicolumn{2}{|c|}{$\begin{array}{l}\text { Non- } \\
\text { Adherent } \\
(\mathrm{N}=49)\end{array}$} & \multicolumn{2}{|c|}{$\begin{array}{l}\text { Moderate } \\
(\mathrm{N}=100)\end{array}$} & \multicolumn{2}{|c|}{$\begin{array}{l}\text { Adherent } \\
(\mathrm{N}=98)\end{array}$} & \multirow[t]{2}{*}{$\mathbf{F}$} & \multirow[t]{2}{*}{$p$} \\
\hline & M & SD & M & SD & M & SD & & \\
\hline PsW & 38.3 & 31.0 & 46.8 & 27.6 & 46.4 & 25.6 & 0.379 & 0.685 \\
\hline SE & 46.4 & 24.6 & 58.3 & 20.4 & 61.9 & 21.4 & 8.435 & 0.000 \\
\hline $\mathrm{RFa}$ & 58.2 & 29.0 & 66.4 & 20.0 & 62.0 & 23.4 & 2.185 & 0.115 \\
\hline $\mathrm{RFr}$ & 29.1 & 30.8 & 37.5 & 29.8 & 39.9 & 48.4 & 1.327 & 0.267 \\
\hline RE & 50.5 & 20.4 & 58.9 & 21.9 & 58.0 & 24.1 & 1.155 & 0.317 \\
\hline PhW & 46.6 & 24.9 & 45.8 & 24.4 & 48.7 & 24.2 & 0.872 & 0.419 \\
\hline $\mathrm{AU}$ & 51.1 & 24.3 & 57.4 & 22.2 & 59.9 & 19.7 & 2.478 & 0.086 \\
\hline SL & 65.5 & 18.9 & 70.1 & 15.7 & 68.6 & 18.2 & 1.816 & 0.165 \\
\hline Index & 48.7 & 15.9 & 55.1 & 12.8 & 55.7 & 14.8 & 4.370 & 0.014 \\
\hline
\end{tabular}

Notes: $M$, mean; SD, standard deviation; $N$, number of people; F, statistical F; $p$, significance; values in bold indicate a statistically significant $(p<0.05)$; S-QoLI8, High scores suggest a better quality of life; DAI-10, High scores suggest a better attitude towards medication.

Abbreviations: S-QoLI8, PsW psychological well-being; SE, self-esteem; RFa, family relationships; RFr, relationships with friends; RE, resilience; PhW, physical well-being; AU, autonomy; SL, sentimental life; DAI-10, Drug Attitude Inventory (non-adherent, moderately adherent, and adherent).

Table 4 Post Hoc Analysis (One-Way ANOVA) with Statistically Significant Differences

\begin{tabular}{|l|l|l|l|l|l|l|}
\hline & \multicolumn{2}{|l|}{ Comparison } & \multicolumn{2}{l|}{$\begin{array}{l}\text { Mean } \\
\text { Difference }\end{array}$} & SE & $\boldsymbol{p}$ \\
\cline { 2 - 6 } & Condition & & Condition & & \\
\hline \multirow{2}{*}{ SE } & $\begin{array}{l}\text { Non- } \\
\text { adherent }\end{array}$ & - & Moderate & -11.82 & 3.77 & $\mathbf{0 . 0 0 6}$ \\
& Moderate & - & Adherent & -15.43 & 3.79 & $\mathbf{0 . 0 0 0}$ \\
& Adherent & -3.61 & 3.07 & 0.726 \\
\hline \multirow{2}{*}{ Index } & $\begin{array}{l}\text { Non- } \\
\text { adherent }\end{array}$ & - & Moderate & -6.40 & 2.48 & $\mathbf{0 . 0 3 2}$ \\
& Moderate & - & Adherent & -6.98 & 2.49 & $\mathbf{0 . 0 1 6}$ \\
& Adherent & -0.58 & 1.03 & 1.000 \\
\hline
\end{tabular}

Notes: SE, standard error; $p$, significance; values in bold indicate a statistically significant $(p<0.05)$; S-QoLI8, High scores suggest a better quality of life; DAI10, High scores suggest a better attitude towards medication; post hoc analyses of multiple comparisons are corrected using Bonferroni's method.

Abbreviations: S-QoL I8, SE self-esteem; DAI-10, Drug Attitude Inventory (nonadherent, moderately adherent, and adherent).

this result are probably that being aware of the disease would be associated with increased depressive symptomatology, substance abuse, and being more likely to be stigmatized, which will impact periods of non-adherence, which could consequently affect patients' QoL. ${ }^{43,44}$

Sociodemographic variables were also associated with QoL. This result suggests that women, older patients, those with lower education levels, and those belonging to an ethnic group may have lower QoL levels. These findings are consistent with those of previous studies in similar samples. ${ }^{17,45,46}$

Although some of the clinical and socio-demographic variables showed major impacts within the regression models, adherence to antipsychotic treatment also has an impact on QoL levels. Therefore, in order to improve the quality of life of patients diagnosed with schizophrenia, interventions that promote adherence to pharmacological treatment should be essential in mental health services, with special attention to non-adherent patients and adjustment of the sociodemographic and clinical profile mentioned above.

The medication non-adherence rate of $19.8 \%$ was lower than that reported in other studies where the expected range was $25 \%-78 \% .^{21,47-49}$ The moderate mean of the total DAI score in this sample reflects a general positive attitude toward antipsychotic medication. This result is to be expected, since the study considers patients who have received community and outpatient treatment in mental health services. ${ }^{10}$ However, a previous study (part of the larger International Research Project) showed a difference between the countries involved in this research where patients in Chile reported greater adherence to medication. ${ }^{13}$ This last point can be explained by the Mental health policies in Chile, where there is a program Garantías Explícitas en Salud (GES) (Explicit Health Guarantees) that constitute a set of benefits guaranteed by law for individuals diagnosed with schizophrenia and other disorders, which ensures the delivery of antipsychotic medication to the patient, unlike Peru and Bolivia, where access to medication is not universal for the population of patients diagnosed with schizophrenia. ${ }^{50}$

This study has two limitations. First, the self-report measure used to assess adherence to antipsychotic treatment has not been without its critics, particularly because of the subjective way in which adherence is assessed as opposed to other methods such as pill counting, electronic monitoring, and/or plasma concentrations, which are characterized as being more quantifiable. Patient behaviors with regard to pharmacological adherence are not easy to detect and quantify, so any form of detection has limitations. However, there is evidence that mental health service users can make reliable ratings of the outcome data. ${ }^{51}$ Second, the research design used in this research, being non-experimental and transversal, prevents the establishment of causal relationships, and is vulnerable to omittedvariable bias. Therefore, it is imperative to carry out longitudinal studies to evaluate the stability of these 
findings and provide more evidence about the temporal order among the variables used, and to incorporate others to complement their explanation.

Future studies should consider objective and subjective measures of adherence as well as clinicians' reports. Furthermore, the effect of adherence (non-adherence) to treatments with first or second-generation medicines should be evaluated in a differential way with reference to their respective effect on the quality of life of patients, considering the current occurrence and types of side effects, since the association between adherence and quality of life could be modified. Furthermore, it would be interesting for future research to compare the associations reported in this study, in samples of Aymara and nonAymara patients, in order to evaluate the possible cultural effect.

\section{Conclusion}

This study provides evidence on the association between treatment adherence and QoL of schizophrenia patients; therefore, as in developed countries, improving adherence to antipsychotic medication would seem to be essential to improve the quality of life of patients in Latin America. These findings should be an input for designing interventions to promote adherence to antipsychotic medication in mental health services.

\section{Funding}

This research was funded in part by the Universidad de Tarapacá through Proyecto Mayor de Investigación Científica y Tecnológica UTA no. 3732-16.

\section{Disclosure}

The authors declare that they have no conflicts of interest for this work.

\section{References}

1. Misdrahi D, Tessier A, Swendsen J, et al. For FACE-SZ (FondaMental Academic Centers of Expertise for Schizophrenia) Group. Determination of adherence profiles in schizophrenia using self-reported adherence: results from the FACE-SZ dataset. $J$ Clin Psychiatry. 2016;77(9):e1130-e1136. doi:10.4088/jcp.15m10115

2. Wang X, Zhang W, Ma N, et al. Adherence to antipsychotic medication by community-based patients with schizophrenia in China: a cross-sectional study. Psychiatr Serv. 2016;67(4):431-437. doi:10. 1176/appi.ps.201500056

3. Nitzan U, Bukobza G, Aviram S, et al. Rebelliousness in patients suffering from schizophrenia-spectrum disorders - a possible predictor of adherence. Psychiatr Res. 2013;209(3):297-301. doi:10.1016/j. psychres.2012.12.028
4. Velligan D, Weiden P, Sajatovic M, et al. For expert consensus panel on adherence problems in serious and persistent mental illness. The expert consensus guideline series: adherence problems in patients with serious and persistent mental illness. J Clin Psychiatry. 2009;70(4):1-46.

5. Lieberman J, Stroup T, McEvoy J, et al. Effectiveness of antipsychotic drugs in patients with chronic schizophrenia. $N$ Engl J Med. 2005;353(12):1209-1223. doi:10.1056/NEJMoa051688

6. Lacro J, Dunn L, Dolder C, et al. Prevalence of and risk factors for medication nonadherence in patients with schizophrenia: a comprehensive review of recent literature. $J$ Clin Psychiatry. 2002;63(10):892-909. doi:10.4088/JCP.v63n1007

7. Barnes T, Paton C. Antipsychotic polypharmacy in schizophrenia. CNS Drugs. 2011;25(5):383-399. doi:10.2165/11587810-000000000-00000

8. Barkhof E, Meijer C, de Sonneville L, et al. Interventions to improve adherence to antipsychotic medication in patients with schizophrenia-a review of the past decade. Eur Psychiatry. 2012;27(1):9-18. doi:10.1016/j.eurpsy.2011.02.005

9. Puschner B, Born B, Giessler A, et al. Adherence to medication and quality of life in people with schizophrenia: results of a European multicenter study. J Nerv Mental Dis. 2006;194(10):746-752. doi:10.1097/01.nmd.0000243082.75008.e7

10. Widschwendter C, Kemmler G, Rettenbacher M, et al. Subjective well-being, drug attitude, and changes in symptomatology in chronic schizophrenia patients starting treatment with new-generation antipsychotic medication. BMC Psychiatry. 2018;18(1):1-9. doi:10.1186/ s12888-018-1791-y

11. Hofer A, Fleischhacker W. Compliance with treatment and its relevance for the management of schizophrenia. Hot Topics Neurol Psychiatr. 2011;11(1):7-13.

12. Hernandez M, Barrio C. Families and medication use and adherence among Latinos with schizophrenia. J Ment Health. 2017;26(1):14-20. doi:10.1080/09638237.2016.1222061

13. Caqueo-Urízar A, Urzúa A, Fond G, et al. Medication non-adherence among South American patients with schizophrenia. Patient Prefer Adherence. 2017;11(1):1737-1744. doi:10.2147/PPA.S144961

14. Medina E, Salvà J, Ampudia R, et al. Short-term clinical stability and lack of insight are associated with a negative attitude towards antipsychotic treatment at discharge in patients with schizophrenia and bipolar disorder. Patient Prefer Adherence. 2012;6(1):623-629. doi:10.2147/PPA.S34345

15. Vassileva I, Milanova V. Attitudes toward antipsychotic medication, insight and psychopathology in outpatients with schizophrenia. Folia Med. 2012;54(4):62-68. doi:10.2478/v10153-012-0007-3

16. Andrianarisoa M, Boyer L, Godin O, et al. Childhood trauma, depression and negative symptoms are independently associated with impaired quality of life in schizophrenia. Results from the national FACE-SZ cohort. Schizophr Res. 2017;185(1):173-181. doi:10.1016/ j.schres.2016.12.021

17. Saleem F, Hassali M, Shafie A, et al. Does treatment adherence correlate with health related quality of life? Findings from a cross sectional study. BMC Public Health. 2012;12(1):318. doi:10.1186/ 1471-2458-12-318

18. Puschner B, Angermeyer M, Leese M, et al. Course of adherence to medication and quality of life in people with schizophrenia. Psychiatry Res. 2009;165(3):224-233. doi:10.1016/j.psychres.2007.10.011

19. Coldham E, Addington J, Addington D. Medication adherence of individuals with a first episode of psychosis. Acta Psychiatr Scand. 2002;106(4):286-290. doi:10.1034/j.1600-0447.2002.02437.x

20. Velligan D, Sajatovic M, Hatch A, et al. Why do psychiatric patients stop antipsychotic medication? A systematic review of reasons for nonadherence to medication in patients with serious mental illness. Patient Prefer Adherence. 2017;11(1):449. doi:10.2147/PPA.S124658

21. Adelufosi A, Adebowale T, Abayomi O, et al. Medication adherence and quality of life among Nigerian outpatients with schizophrenia. Gen Hosp Psychiatry. 2012;34(1):72-79. doi:10. 1016/j.genhosppsych.2011.09.001 
22. Endriyani L, Chien C, Huang X, et al. The influence of adherence to antipsychotics medication on the quality of life among patients with schizophrenia in Indonesia. Perspect Psychiatr Care. 2018;55 (2):147-152. doi: $10.1111 /$ ppc. 12276

23. Hayhurst K, Drake R, Massie J, et al. Improved quality of life over one year is associated with improved adherence in patients with schizophrenia. Eur Psychiatry. 2014;29:191-196. doi:10.1016/j. eurpsy.2013.03.002

24. Ng C, Smith D, King J, et al. Medication attitudes and beliefs in patients with psychotic and affective disorders on maintenance treatment. Hum Psychopharmacol. 2012;27(1):57-62. doi:10.1002/ hup. 1264

25. World Health Organization. ICD-10 Classifications of Mental and Behavioural Disorder: Clinical Descriptions and Diagnostic Guidelines. Geneva: World Health Organization; 1992.

26. Hogan T, Awad A, Eastwood R. A self-report scale predictive of drug compliance in schizophrenics: reliability and discriminative validity. Psychol Med. 1983;13(1):177-183. doi:10.1017/S0033291700050182

27. Nielsen R, Lindström E, Nielsen J, et al. DAI-10 is as good as DAI-30 in schizophrenia. Eur Neuropsychopharmacol. 2012;22 (10):747-750. doi:10.1016/j.euroneuro.2012.02.008

28. Saleem F, Hassali M, Shafie A, et al. Association between knowledge and drug adherence in patients with hypertension in Quetta, Pakistan. Trop J Pharm Res. 2011;10(2):125-132. doi:10.4314/tjpr. v10i2.66552

29. Ramírez F, Robles R, Salazar V, et al. Evaluación de actitudes al medicamento en pacientes con esquizofrenia propiedades psicométricas de la versión en español del DAI. Actas Esp Psiquiatr. 2004;32(3):138-142.

30. Boyer L, Simeoni M, Loundou A, et al. The development of the S-QoL 18: a shortened quality of life questionnaire for patients with schizophrenia. Schizophr Res. 2010;121(1-3):241-250. doi:10.1016/ j.schres.2010.05.019

31. Caqueo-Urízar A, Boyer L, Boucekine M, et al. Spanish cross-cultural adaptation and psychometric properties of the Schizophrenia Quality of Life short-version questionnaire (SQoL18) in 3 middle-income countries: Bolivia, Chile, and Peru. Schizophr Res. 2014;159(1):136-143. doi:10.1016/j.schres.2014.08.013

32. Carreño A. Revisiter les frontières et réparer 1'histoire.Itinéraires thérapeutiques et processus de sauvegarde de la médecine traditionnelle andine dans un contexte transnational. Anthropologie Santé. 2013;6(1):1-18. doi:10.4000/anthropologiesante.1087

33. Kay S, Fiszbein A, Opler L. The positive and negative syndrome scale (PANSS) for schizophrenia. Schizophr Bull. 1987;13 (2):261-276. doi:10.1093/schbul/13.2.261

34. Peralta V, Cuesta M. Validation of positive and negative symptom scale (PANSS) in a sample of Spanish schizophrenic patients. Actas Luso Esp Neurol Psiquiatr Cienc Afines. 1994;22(4):171-177.

35. Amador X, Strauss D. Poor insight in schizophrenia. Psychiatr $Q$. 1993;64(4):305-318. doi:10.1007/BF01064924

36. Ruiz A, Pousa E, Duñó R, et al. Spanish adaptation of the Scale to Assess Unawareness of Mental Disorder (SUMD). Actas Esp Psiquiatr. 2008;36(2):111-1198.

37. IBM Corp. IBM SPSS Statistics for Windows, Version 25.0. Armonk, NY: IBM Corp; 2017.
38. Acosta F, Ramallo-Fariña Y, Siris S. Should full adherence be a necessary goal in schizophrenia? Full versus non-full adherence to antipsychotic treatment. Compr Psychiatry. 2014;55(1):33-39. doi:10.1016/j.comppsych.2013.09.005

39. Fujikawa M, Togo T, Yoshimi A, et al. Evaluation of subjective treatment satisfaction with antipsychotics in schizophrenia patients. Prog Neuropsychopharmacol Biol Psychiatry. 2008;32(3):755-760. doi:10.1016/j.pnpbp.2007.12.002

40. Arraras J, Ibañez B, Basterra I, et al. Determinants of quality of life in Spanish outpatients with schizophrenia spectrum disorders. Eur J Psychiatry. 2018;32(3):113-121. doi:10.1016/j.ejpsy.2017.11.001

41. Alessandrini M, Lançon C, Fond G, et al. A structural equation modelling approach to explore the determinants of quality of life in schizophrenia. Schizophr Res. 2016;171(1-3):27-34. doi:10.1016/j. schres.2016.01.012

42. Liu-Seifert H, Osuntokun O, Godfrey J, et al. Patient perspectives on antipsychotic treatments and their association with clinical outcomes. Patient Prefer Adherence. 2010;4:369-377. doi:10.2147/ppa.s12461

43. Shuler K. Approaches to improve adherence to pharmacotherapy in patients with schizophrenia. Patient Prefer Adherence. 2014;8:701-714. doi:10.2147/PPA.S59371

44. Boyer L, Aghababian V, Richieri R, et al. Insight into illness, neurocognition and quality of life in schizophrenia. Prog Neuropsychopharmacol Biol Psychiatry. 2012;36(2):271-276. doi:10.1016/j.pnpbp.2011.10.008

45. Guedes de Pinho L, Pereira A, Chaves C. Quality of life in schizophrenic patients: the influence of sociodemographic and clinical characteristics and satisfaction with social support. Trends Psychiatry Psychother. 2018;40(3):202-209. doi:10.1590/22376089-2017-0002

46. Xiang Y, Wang C, Wang Y, et al. Socio-demographic and clinical determinants of quality of life in Chinese patients with schizophrenia: a prospective study. Qual Life Res. 2010;19(3):317-322. doi:10.1007/ s11136-010-9593-9

47. Nose M, Barbui C, Tansella M. How often do patients with psychosis fail to adhere to treatment programmes? A systematic review. Psychol Med. 2005;33(7):1149-1160. doi:10.1017/s0033291703008328

48. Adewuya A, Owoeye O, Erinfolami A, et al. Prevalence and correlates for poor medication adherence amongst psychiatric outpatients in Southwestern Nigeria. Gen Hosp Psychiatry. 2009;31(2):364-368. doi:10.1016/j.genhosppsych.2008.12.005

49. Adeponle A, Baduku A, Adelekan M, et al. Prospective study of psychiatric follow-up default and medication compliance after discharge at a psychiatric hospital in Nigeria. Community Ment Health J. 2009;45(1):19-25. doi:10.1007/s10597-008-9155-6

50. de Salud M. Guía Clínica: para el tratamiento de personas desde el primer episodio de esquizofrenia [clinical guidelines: for the treatment of people from the first episode of schizophrenia]. Santiago: MINSAL; 2016. Available from: https://www.normassalud.com/docu mentos/chile/guia_esquizofrenia_2017.pdf. Accessed October 20, 2016.

51. Thornicroft G, Tansella M. Growing recognition of the importance of services user involvement in mental health services planning and evaluation. Epidemiol Psichiatr Soc. 2005;14(1):1-3. doi:10.1017/ S1121189X00001858 


\section{Publish your work in this journal}

Patient Preference and Adherence is an international, peer-reviewed, open access journal that focusing on the growing importance of patient preference and adherence throughout the therapeutic continuum. Patient satisfaction, acceptability, quality of life, compliance, persistence and their role in developing new therapeutic modalities and compounds to optimize clinical outcomes for existing disease states are major areas of interest for the journal. This journal has been accepted for indexing on PubMed Central. The manuscript management system is completely online and includes a very quick and fair peer-review system, which is all easy to use. Visit http:// www.dovepress.com/testimonials.php to read real quotes from published authors. 